\title{
The sudden death of a 6.6 year old girl due to anaphylactic shock caused by nonruptured echinococcal cysts of the left ventricle and the liver
}

\author{
Hidajeta Begić ${ }^{1}$, Jasminka Mustedanagić-Mujanović ${ }^{2}$, \\ Elmir Čičkušić ${ }^{2}$, Husref Tahirović ${ }^{3}$
}

${ }^{1}$ Department of Paediatrics

${ }^{2}$ Department of Pathology and

${ }^{3}$ Department for research and education University Clinical Centre Tuzla Bosnia and Herzegovina

bbs.enes@bih.net.ba

Tel.: + 035303740

Fax: + 035303740

Received: 29 September 2011

Accepted: 20 November 2011

Copyright (C) 2011 by

Academy of Sciences and Arts

of Bosnia and Herzegovina.

E-mail for permission to publish:

amabih@anubih.ba

A 6.6-year-old girl presented for left sided cardiac enlargement on chest radiography (Panel A). Three years earlier she had undergone a lobectomy of the lower lobe of the left lung for extraction of an echinococcal cyst. After that she was well, without any medication. There was a 3/6 systolic murmur at the heart apex with ECG signs of left ventricular hypertrophy.

An echocardiogram showed the dilated left ventricle, LVDd 50 $\mathrm{mm}$, filled with a cyst $45 \times 35 \mathrm{~mm}$ in diameter (Panel B), with moderate mitral regurgitation and normal aortic flow. A CT scan showed a cystic lesion in the lumen of the left ventricle, $50 \times 40 \mathrm{~mm}$ and in the left lobe of the liver one of $60 \times 60$ mm (Panels C and D). During the first cycle of treatment with abendazol the child suddenly died due to anaphylactic shock reaction.

At the autopsy expressed generalized cyanosis was found. The presence was established of an intact echinococcal cyst, $40 \times 50 \mathrm{~mm}$ in the inventricular septum of the heart with reduction of the lumen and hypertrophy of the wall of the left ventricle, (Panel E). By microscope eosinophilic myocarditis was found. The medial part of the left lobe of the liver was enlarged due to an echinococcal cyst, $100 \times 60 \mathrm{~mm}$ with the signs of eosinophilic inflammation at the neighbouring parenchyma. On the lungs an oedema was noted, with microscopic bleeding and eosinophilic interstitial inflammation, but with no elements of an echinococcal cyst.

Conflict of interest: The authors declare that they have no conflict of interest. This case was not sponsored by any external organisation.
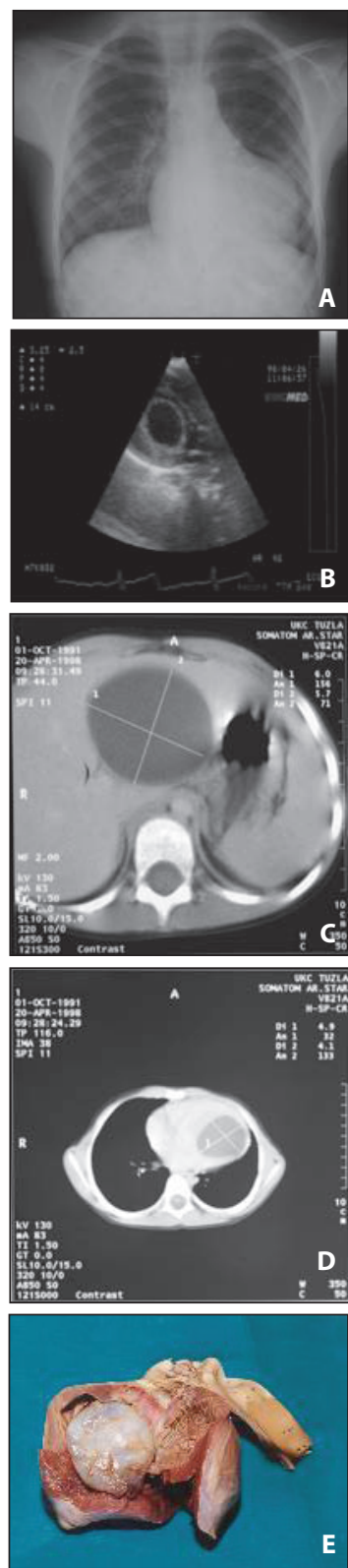